\title{
Restoring Fun to Game Theory
}

\section{Avinash Dixit}

Abstract: The author suggests methods for teaching game theory at an introductory level, using interactive games to be played in the classroom or in computer clusters, clips from movies to be screened and discussed, and excerpts from novels and historical books to be read and discussed.

JEL codes: A22, C70

Game theory starts with an unfair advantage over most other scientific subjects-it is applicable to numerous interesting and thought-provoking aspects of decisionmaking in economics, business, politics, social interactions, and indeed to much of everyday life, making it automatically appealing to students. However, too many teachers and textbook authors lose this advantage by treating the subject in such an abstract and formal way that the students' eyes glaze over. Even the interests of the abstract theorists will be better served if introductory courses are motivated using examples and classroom games that engage the students' interest and encourage them to go on to more advanced courses. This will create larger audiences for the abstract game theorists; then they can teach students the mathematics and the rigor that are surely important aspects of the subject at the higher levels.

Game theory has become a part of the basic framework of economics, along with, or even replacing in many contexts, the traditional supply-demand framework in partial and general equilibrium. Therefore economics students should be introduced to game theory right at the beginning of their studies. Teachers of economics usually introduce game theory by using economics applications; Cournot duopoly is the favorite vehicle. However, I prefer a different approach. Even before anyone is exposed to any economics, everyone has been involved in many strategic games. Undergraduates have played such games with siblings, friends, and parents; strategy is an important aspect of many sports they have played and watched; and many movies and books have themes or episodes with game-theoretic content. Following the time-honored principle of teaching that one should start with what the students already know and proceed to build on it, I prefer to teach introductory game theory by using examples drawn from such sources. ${ }^{1}$ I have found that this approach makes it not only possible, but also productive and enjoyable, to introduce game theory at an elementary level in colleges and even in the better high schools.

In the early days of game theory, even the mathematicians who created its foundations showed a sense of fun. Von Neumann and Morgenstern (1953, 176-78)

Avinash Dixit is a professor of economics at Princeton University (e-mail: dixitak@princeton.edu). The author thanks William Becker for comments on a preliminary draft. 
expounded mixed strategy equilibria using the story of Sherlock Holmes trying to evade the pursuing Professor Moriarty. Williams (1966) gave an exposition of twoperson zero-sum minimax theory by using many amusing examples, although they verged on the trivial because of the restricted scope. Tucker's 1950 invention of the story of the prisoner's dilemma (Nasar 1998, 118) was surely a stroke of genius. Most recent theorists have been comparatively humorless, even though they invent amusing names, such as the centipede, horse, or beer-quiche, for their mathematical examples. It is time fun came back to game theory.

I have developed such an elementary course and taught it at Princeton for several years. Susan Skeath has done the same at Wellesley. We have written a textbook (Dixit and Skeath 2004), now in its second edition, for such a course, comparable in level and style to any introductory or principles textbook in economics, political science, or natural sciences. In this article, I offer some teaching ideas and tricks that I have learned from this experience.

I restrict most of my remarks to the teaching of game theory per se and not as a part of an economics course. This is because I hold a rather radical view: An introduction to game theory should precede, not follow, the introductory economics courses in micro and macro. Knowing the concepts of strategy, rollback, and Nash equilibrium helps one unify many apparently distinct ideas and phenomena in economics. Therefore, previous knowledge of elementary game theory will make learning economics easier. For example, if students already know assurance games, Keynesian unemployment becomes a coordination failure leading to a wrong equilibrium selection, rather than a mysterious crossing of two graphs, and many market failures in micro fall into the common framework of the prisoner's dilemma. Also, the view of competition as live interaction of strategies is more appealing to beginners than that of an impersonal adjustment of prices by an invisible hand. Elaboration of this theme of teaching economics with game theory merits an article by itself; however, I believe that approach to be appropriate for an intermediate level of teaching game theory to economics students, whereas here I focus on the introductory level.

\section{GAMES IN CLASS}

Playing a few well-designed games in class and watching others play them brings to life the concepts of strategy, backward induction, and Nash equilibrium far better than any amount of formal statement or problem-set drill. Indeed, I like to start my game theory course with two classroom games, before teaching or even mentioning any of these concepts at all. The concepts emerge naturally during the discussion of each game.

\section{A Sequential-Move Game}

This simple Nim-like game can be played in many formats. A particularly attractive one comes from its use in one of the "Survivor" TV series, namely episode 6 of "Survivor Thailand," which aired in fall 2002. In this episode, there 
were 21 flags and two players, who alternated in taking turns to remove some flags. At each turn, the player had to remove 1, 2, or 3 flags; this was the player's choice at each move. The player who removed the last flag (whether as the sole remaining flag or one of the last surviving set of 2 or 3 flags) was the winner. Instead of using flags, the instructor can use coins; lay them out on the glass of the overhead projector so the whole class can easily see what is going on.

In the "Survivor" show, the game was played as an "immunity challenge" between two teams, called tribes. The losing tribe had to vote out one of its members, weakening it for future competitions. In the specific context, this loss had a crucial effect on the eventual outcome of the game. Thus a million-dollar prize hinged on the ability to do the simple calculation. A video clip of the competition is available from the Web site for the show, http://www.cbs.com/primetime/ survivor5/show/episode06/s5story.shtml. With the right kind of equipment available in the classroom, the instructor can download and show the clip, "More Action at the Immunity Challenge," available from page five of this site. The actual players got almost all of their moves wrong, so seeing it first and then playing a similar game themselves will be a good way for students to learn the concepts.

The correct solution is simple. If player 1 (or team 1) leaves player 2 (or team 2) with four flags, player 2 must remove 1, 2, or 3, and then player 1 can take the rest and win. To make sure that player 1 leaves player 2 with four flags, player 1 must leave player 2 facing eight flags on the immediately preceding turn. The logical sequence then is to leave 12,16 , and 20 on previous turns. Therefore, starting with 21 flags, player 1 should remove one and proceed to take four minus whatever player 2 takes at the immediately preceding turn.

The first time a pair of students play this game, they make choices almost at random. After their game is over, watched by the whole class, the instructor chooses two others. They do better than the first pair; they figure out one or perhaps even two of the final rounds correctly. By the third or at most the fourth time, the players will have figured out the full backward induction.

The instructor should then hold a brief discussion and nudge or guide the discussion a little toward three conclusions. First, the idea of backward induction, or the importance of solving sequential-move games backward from the final moves. Second, the idea of correct strategies that constitute a solution of the game. Tell the students that it will soon be given a formal name, rollback equilibrium. Finally, the idea that one can learn correct strategies by actually playing a game. With this comes the idea that if a game is played by experienced players, one might expect to observe correct strategies and equilibrium outcomes. This will give the students some confidence in the concepts of backward induction and rollback equilibrium.

The last remark motivates a brief digression. Over the past decade, behavioral game theorists have made a valuable contribution to the stock of interesting games that can be played in classrooms. However, many of them come to the subject with a negative agenda, namely to argue that everything in conventional game theory is wrong. My own experience suggests otherwise. To be sure, it takes time and experience merely to understand the rules of any game and a lot of practice and experimentation to play it well; but students learn quite fast. Advanced 
researchers delight in the difficulties of learning and on how actual outcomes can differ from the equilibrium predictions. However, it is counterproductive to give the impression to beginners that what they are about to learn is all wrong; it destroys their whole motivation to learn. I find it better to convey a sense of guarded optimism about the standard Nash theory, without pretending that it closes the subject. Of course, I believe this to be the truth of the matter.

\section{A Simultaneous-Move Game}

My second game is a version of the famous "generalized beauty contest." Choose 10 students in the class and give them blank cards. Each student is to write his or her name on the card and a number between 0 and 100; collect the cards and average the numbers on them. The student whose choice is closest to half of the average is the winner. These rules are of course explained in advance and in public.

The Nash equilibrium of this game is 0 . In fact, it results from an iterated dominance argument. Because the average can never exceed 100, half of the average can never exceed 50. Therefore, any choice above 50 is dominated by 50 . Then the average can never exceed $50, \ldots$ The first time the game is played, the winner is usually close to 25. This fits Nagel's (1995) observation that the outcome is as if the students expect the others to choose at random, averaging 50 , and then choose half of that. Next, choose a different set of 10 students from the class (who have watched the outcome of the first group's game). This second group chooses much smaller numbers, and the winner is close to 10 (as if one more round of the dominance calculation was performed) or even 5 or 6 (as if two more rounds were performed). The third group of 10 chooses much smaller numbers, including several zeros, and the winner's choice is as low as 3 or 4. Incidentally, I have found that learning proceeds somewhat faster by watching others play than when the same group of 10 plays successively. Perhaps the brain does a better job of observation and interpretation if the ego is not engaged in playing the game.

Again, hold a brief discussion. The instructor should bring out the following points:

1. The logical concept of dominance, iterated elimination of dominated strategies, and the culmination in a Nash equilibrium.

2. Getting close to the Nash equilibrium by the experience of playing the game. Whether it is a crucial flaw of the theory that 0 is rarely exactly attained, or the theory gives a good approximation, can be a point to be debated depending on the time available.

3. The idea that if one has a good reason to believe that others will not be playing their Nash equilibrium strategies, then one's optimal choice will also differ from one's own Nash equilibrium strategy.

The discussion can also touch on the question: What if the object is to come closest to the average, not half of the average? That game is, of course, Keynes' famous metaphor for the stock market, where everyone is trying to guess what 
everyone else is trying to guess. The game has multiple Nash equilibria, each sustained by its own bootstraps. Details of this are best postponed to a later point in the course when the instructor covers multiple equilibria more systematically, but a quick mention in the first class provides the students an interesting economic application at the outset. The instructor can also stress the importance of this game in the students' own lives. Part or even all of their retirement funds are likely to be in individual accounts. When they decide how to invest this sum, they will have to think through the question: Will the historical pattern of returns and volatility of various assets persist when everyone makes the same decisions that I am now contemplating? This interaction between individual choice (strategy) and aggregate outcomes (equilibrium) comes naturally to someone who is trained to think in game theories, but others are often liable to forget the effect of everyone's simultaneous choices. In the context of saving for retirement, this can be very costly.

\section{All-Pay Auction}

In later classes, I play several other games, such as the centipede and ultimatum games, and, of course, several variants of prisoners' dilemmas and collective action games, each of which illustrates a basic theoretical concept or some way in which the experience of reality departs from the theory. An amusing climax I have tried in the very last class is the applause auction. Princeton has a tradition that at the end of the instructors' last lectures in each course they get a brief polite round of applause. At this point, I offer a reward, usually $\$ 20$ but sometimes as much as $\$ 50$, to the person who continuously applauds the longest. This is an allpay auction; the students are bidding in kind, namely applause, and all bidders pay their bids, win or lose.

Most students drop out within the first 15 or 20 minutes, but a few remain applauding for absurdly long periods. The record to date is when three students applauded for $4 \frac{1}{2}$ hours. To complete the educational purpose of the game (and to avoid the risk of a headline, "Professor Buys Applause," in the student newspaper), I send an e-mail to the class explaining the game. I point out that all-pay auctions are quite common: The contestants in sporting competitions or elections spend their time, efforts, and money, with no refunds for the losers. Such contests can escalate, and the nuclear arms race was a classic example of overbidding. I refer them to Hirshleifer and Riley (1992, ch. 10) and Bulow and Klemperer (1999) for the theory of such games. I tell them about any interesting special occurrences in that year's competition. One year, for example, six people remained and were discussing splitting the prize; five agreed, but one refused. At that point, the other five got angry and threatened to stay as long as necessary to outlast the sixth. After a few minutes of experiencing the credibility of this threat, the sixth gave up, and then the other five stopped simultaneously to share the prize. This was a nice example of people's instinctive willingness to punish antisocial behavior even at a personal cost (Fehr and Gächter 2000).

The combined experience of teachers of game theory is gradually creating an impressive collection of classroom games. Another recent example is Brokaw and Merz (2004). 


\section{Role-Playing}

Games where the class is split into teams that play different roles in acting out a strategic situation can be very instructive. I have run such sessions, for example, one where terrorists or bank robbers have taken hostages, and the authorities are negotiating for their release, and another on negotiation for peace in the Middle East. I assign some general background reading, but otherwise leave the students to devise their own agendas and strategies. I find that they take these exercises seriously and think hard and well. The Middle East peace negotiation is a case in point. The students devised imaginative and realistic strategies. The Israeli delegation did not show up but instead sent a declaration saying that they would not negotiate until the violence ended. The Palestinian delegation showed up with good intentions but could not credibly promise to control their extreme factions. Finally, the extremist group pulled out water pistols and held everyone hostage! The United Nations delegation should have thought of this and should have posted guards at the door to check backpacks.

Because I give the students a lot of freedom, I have to think ahead and be ready for a large number of alternative scenarios that could develop, but, on occasion, I have been pleasantly surprised by the students' ideas. Other teachers may prefer a somewhat tighter structure, but I think that even they will learn something from such exercises.

\section{Computer Games: The Wild-West Shootout}

Finally, it is possible to program more elaborate games on a computer network. Numerous games of this kind are readily available; Charles Holt of the University of Virginia offers an excellent collection of Web-based games on his Web site, http://www.people.virginia.edu/ cah2k/teaching.html. Vesna Prasnikar of Carnegie Mellon University has software called Comlabgames, and Paul Romer's Webbased educational materials company Aplia (http://www.aplia.com) markets game-playing software. However, I find that many such games are too abstractthey offer matrices or trees to which payoffs can be added, and the students are asked to take the row or column roles. I prefer ones with context and appeal better related to the kinds of computer games students will have played before.

My best such game is a four-person, three-bullet duel. (The name of the game could be "The Good, the Bad, the Bold, and the Beautiful.") Students in the class are seated at terminals in the computer cluster and randomly matched into foursomes. Each person in a foursome sees on his or her screen a square divided into four quadrants; this is schematically reproduced in Figure 1. Each player starts with three bullets, and as long as he or she is still "alive" in the game, can shoot at any of the others at any time. To shoot at a player, the student moves the cursor into the intended victim's quadrant and clicks on the left mouse button. The probability of scoring a hit increases with time, and this is indicated by the shrinkage of a central square that overlaps the four quadrants. At any time, the probability of hitting an adjacent player is higher than that of hitting the diagonally opposite player. The rules handed out at the beginning of the game 
Time remaining $=85$ seconds

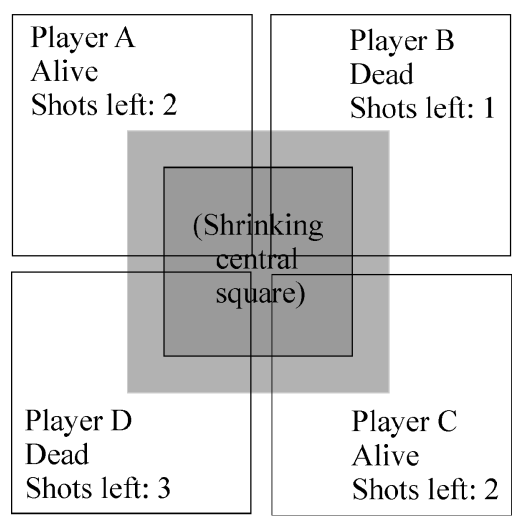

FIGURE 1. The four-person, three-bullet duel.

state the formulas for the increases in probabilities. The total shrinkage time is two minutes. The player's score in any one such play equals the number of seconds the student stays alive, plus a bonus of 50 points if the player is alive at the end of the two minutes, and an additional bonus of 100 points if the student is the only player in the foursome to remain alive at the end of the two minutes (to discourage collusion where no one shoots).

This game is played several times, with varying matches, so that no foursomes are repeated. Indeed, the identity of the others in one's foursome in any one play is not made known. Each student's score for the session is the average over all the games he or she plays. This forms a small part of the course credit, so the stakes are quite high.

There are also sets of repetitions under different information conditions. In the first, every player knows whether each of the others is alive or dead and the number of bullets they have left; this is the condition shown in Figure 1. In the second, each player knows whether the others are alive or dead but not the number of bullets they have left; thus the last of the three information lines does not appear in this set of repetitions. In the third, the players do not even know whether the others are alive or dead; this is as if they are hiding behind a building or a tree in an actual Wild-West shootout.

As far as I know, this game has no analytical solution. My observation from the classroom performance is that reasonably patient strategies do well and that less patience is slightly better in the later limited information conditions but that most students are too impatient and shoot too many bullets too quickly. I have also tried sessions of the game accompanied by suitably tense music (Bolero or the James Bond theme) and found, as expected, that this leads to itchier fingers on the trigger. Playing this game several times and in different information conditions gives the students a good hands-on way of learning how to develop heuristics for games in which the calculation of Nash equilibrium is too difficult. (See Simon and 
Schaeffer 1992; Dixit and Skeath 2004, sec. 3.5B, for a discussion of chess from this perspective.)

This game has its counterparts in economics and business. The general idea is that you face a tradeoff between shooting late to increase the probability of scoring a hit and shooting early to reduce the risk of getting shot by someone else. This is the same situation that firms in high-technology industries face when they are deciding when to introduce a new product — wait to make it more perfect or rush to be first in the market? The game gives students an interesting hands-on experience of the calculation and the tension involved in such decisions.

The code for the game is specific to Princeton's computer cluster system, but if instructors want to implement the game in their own institution, any competent computer science major should be able to write the code for the cluster during the summer between junior and senior years. I have implemented two other gamesa prisoner's dilemma and a bargaining game - and can supply similar information about them on request for teachers who want to get them programmed at their schools.

\section{Some Advice for Conducting Classroom Games}

My experience leads me to make some suggestions on how to, and how not to, conduct such games. First, use real money for prizes. Even small amounts raise student interest and attention. The students' scores in the game can count for a small fraction of the course credit but do not choose games where the outcome depends significantly on chance rather than skill. Next, use games with stories, not just abstract trees or matrices, but do not make the story of the game so complex that the main conceptual point is smothered. Finally, follow each game immediately with a discussion that brings out the general concepts or methods of analysis that the game was supposed to illustrate. If there is not enough time for a good discussion, circulate an explanation or post it on the course Web site.

\section{MOVIES AND TV SHOWS}

Many movies contain scenes that illustrate some aspect of strategic interaction. These scenes can be screened in class as an introduction to that topic, and a discussion can lead to theoretical analysis of it.

\section{Nash Equilibrium}

One cannot ask for a better movie to get students to improve their understanding of this basic concept of game theory than A Beautiful Mind, which was based, however loosely, on the life of John Nash himself, and in turn on Nasar's (1998) biography, which, although it emphasized the psychological and mental aspects, gave a correct account of the Nash equilibrium concept. The crucial scene from the movie, where Nash is supposed to have discovered his concept of equilibrium, shows him in a bar with three male friends. A blonde and her four brunette friends walk in. All 
four men would like to win the blonde's favor. However, if they all approach her, each will stand at best a one-fourth chance; actually, the movie seems to suggest that she would reject all four. The men will have to turn to the brunettes, but then the brunettes will reject them also, because "no one likes to be second choice." In the movie, Nash says that the solution is for them all to ignore the blonde and go for the brunettes. One of the other men thinks this is just a ploy on Nash's part to get the others to go for the brunettes so he can be the blonde's sole suitor. If one thinks about the situation using game theory, the Nash character is wrong and the friend is right. The strategy profile where all men go for the brunettes is not a Nash equilibrium: Given the strategies of the others, any one of them gains by deviating and going for the blonde. In fact, Anderson and Engers (2002) show that the game has multiple equilibria, but the only outcome that cannot be a Nash equilibrium is the supposedly brilliant solution found by the Nash character!

\section{Mixed Strategies}

The concept of mixed strategies is often initially counterintuitive. Although many situations in sports serve to introduce it, I like one scene from The Princess Bride, a whimsical comedy that has the added advantage of being a favorite teen movie. In this scene, the hero (Westley) challenges one of the villains (Vizzini) to a duel of wits. Westley will poison one of two wine cups without Vizzini observing his action and set one in front of each of them. Vizzini will decide from which cup he will drink; Westley then must drink from the other cup. Vizzini goes through a whole sequence of arguments as to why Westley would or would not choose to poison one cup or the other. Finally, he believes he knows which cup is safe and drinks from it. Westley drinks from the other. Just as Vizzini is laughing and advising Westley to "never go against a Sicilian when death is on the line," Vizzini drops dead.

Pause the videotape or disc at this point and have a brief discussion. The students will quickly see that each of Vizzini's arguments is inherently selfcontradictory. If Westley thinks through to the same point that leads Vizzini to believe that a particular cup will contain the poison, he should instead put the poison in the other cup. Any systematic action can be thought through and defeated by the other player. Therefore, the only correct strategy is to be unsystematic or random.

\section{Asymmetric Information}

Actually, this is not the main point of the story. Resume the tape or disc. The princess is surprised to find that Westley had put the poison in the cup he placed closer to himself. "They were both poisoned," he replies. "I have been building up immunity to Iocaine for years." Thus the game being played was really one of asymmetric information; Vizzini did not know Westley's payoffs and did not think the strategy of poisoning both cups was open to him. At this point, you can show a clip from another movie classic, Guys and Dolls. Sky Masterson recalls advice from his father: "Son, no matter how far you travel, or how smart you get, always remember this: Some day, somewhere, a guy is going to come to you and 
show you a nice brand-new deck of cards on which the seal is never broken, and this guy is going to offer to bet you that the jack of spades will jump out of this deck and squirt cider in your ear. But son, do not bet him, for as sure as you do you are going to get an ear full of cider" (Runyon 1933 [1992]).

\section{Brinkmanship}

Many movies have scenes that deal with the question of how to get some vital information that only your adversary possesses because he knows that the threat of killing him is not credible. The situation plays out differently in High Wind in Jamaica, Crimson Tide, The Maltese Falcon, and The Gods Must Be Crazy. You can show excerpts from all four and then hold a discussion to compare and contrast them.

In High Wind in Jamaica, the pirate captain, Chavez (the information seeker), backs off and tries a different approach. In Crimson Tide, the U.S. Navy submarine captain Ramsey threatens to kill a co-conspirator of the person who has the crucial firing codes for the submarine's missiles. This works; the person gives up the code. The conspirators were trying to prevent the start of a possibly unnecessary nuclear war in which millions would die, but it is interesting that the immediate death of someone you know can weigh more in your calculation than abstract megadeaths.

In The Maltese Falcon, the hero, Samuel Spade (played by Humphrey Bogart), is the only person who knows where the priceless gem-studded falcon is hidden, and the chief villain, Caspar Gutman (Sydney Greenstreet), is threatening him for this information. This produces a classic exchange, here cited from the book (Hammett 1930, 223-24) but reproduced almost verbatim in the movie.

Spade flung his words out with a brutal sort of carelessness that gave them more weight than they could have got from dramatic emphasis or from loudness. "If you kill me, how are you going to get the bird? If I know you can't afford to kill me till you have it, how are you going to scare me into giving it to you?"

Gutman cocked his head to the left and considered these questions. His eyes twinkled between puckered lids. Presently, he gave his genial answer: "Well, sir, there are other means of persuasion besides killing and threatening to kill."

"Sure," Spade agreed, "but they're not much good unless the threat of death is behind them to hold the victim down. See what I mean? If you try something I don't like I won't stand for it. I'll make it a matter of your having to call it off or kill me, knowing you can't afford to kill me."

"I see what you mean." Gutman chuckled. "That is an attitude, sir, that calls for the most delicate judgment on both sides, because, as you know, sir, men are likely to forget in the heat of action where their best interests lie and let their emotions carry them away."

Spade too was all smiling blandness. "That's the trick, from my side," he said, "to make my play strong enough that it ties you up, but yet not make you mad enough to bump me off against your better judgment."

The class discussion can explore the nature of these strategies. The scene can be seen as an example of Schelling's (1960, 17-18) idea of the (strategic) rationality of (seeming) irrationality; Gutman is making his threat credible by pointing out that he may act irrationally. It is better seen as an example of the dynamic game of 
brinkmanship (Schelling 1960, ch. 8; 1966, ch. 3). Both parties, by persisting in their actions-Gutman in his torture and Spade in his defiance-are raising the risk that Gutman may get angry and do something against his own rational interest. Each is exploring the risk tolerance of the other, in the hope that it is lower than his own risk tolerance so that the other will blink first. A more formal analysis of this in the context of the Cuban missile crisis is found in Dixit and Skeath (2004, ch. 14).

The scene from The Gods Must Be Crazy makes this escalation of risk more explicit. An assassination attempt on the dictator of an African country has failed, and one of the team of gunmen has been captured. He is being interrogated for the location of the group's headquarters and the leader. The scene is the inside of a helicopter. The blindfolded gunman is standing with his back to the open door. Above the noise of the rotors, the army officer questions the gunman a couple of times and gets only shakes of the head. Then he simply pushes the gunman out the door. The scene switches to the outside of the helicopter, which we now see is just barely hovering above the ground, and the gunman has fallen six feet on to his back. The army officer appears at the door and says, "The next time it will be a little bit higher."

Brinkmanship arises in many economic contexts, most notably that of wage bargaining where the risk of a strike or a lockout increases as protracted negotiations fail to produce results. Understanding the subtleties and the risks of this strategy is therefore an important part of an economist's education, and these movie scenes illustrate it in memorable ways.

\section{Dr. Strangelove}

This is a universal favorite strategic movie; it illustrates many issues of commitments, threats, and promises, all within a compelling narrative full of tension and satirical humor. Two scenes in the Pentagon war room are essential viewing: (a) the one in which the U.S. President Merkin Muffley hears how General Ripper has made irreversible his unauthorized launching of a nuclear attack on the Soviet Union by cutting off all communication with his base and with the aircraft and $(b)$ the one in which Dr. Strangelove explains why the doomsday machine is such a credible deterrent. When the president asks, "But how is it possible for the machine to be triggered automatically and yet impossible to de-trigger?" Strangelove replies, "Mr. President, it is not only possible; it is essential. That is the whole idea." Then he asks the Soviet ambassador, "But the whole point of the machine is lost if you keep it a secret. Why didn't you tell the world?"

There are numerous other incidents in the movie that illustrate other points of strategy, and a good case can be made for screening the whole movie and discussing it. However, the context of the cold war may be too dated for today's students, and they may find the period atmosphere-the black-and-white film, the sexist jokes - unappealing. With a little prior explanation of the context and warnings that the offensive-sounding bits are satirical, my students have enjoyed the movie; however, a large fraction of them (having been brainwashed by Hollywood) expected to the last minute that there would be a happy ending in which somehow the plane would be recalled. 
These movies are just a few of the large collection that is available; I am sure other teachers have their own different favorites. Television can also be a good source. Trandel (1999) offers an early example from a game show. Many episodes of the BBC sitcoms "Yes, Minister" and "Yes, Prime Minister" are outstanding lessons in strategy: bargaining, commitment, signaling, and screening. Unfortunately, the setting is too unfamiliar to non-British students, and the period is also getting dated for many of them, even though it is barely 10 to 20 years ago. Finally, in the first of the CBS "Survivor" series, the eventual winner, Richard Hatch, used a clever "losing to win" strategy to get to the final twosome. This is too lengthy to explain here, but the scene is available from the CBS Web site http://www.cbs.com/primetime/survivor/show/episode13/story.shtml. The immunity challenge when three players are left is the crucial scene. A game-theorybased analysis is found in Dixit and Skeath (2004, sec. 3.7).

\section{Advice for Movie Screenings}

As with classroom games, my own experience of movie screenings leads me to make some suggestions. First, instructors should take suggestions from students about other movies or games the class can use-students' ideas are more likely to be appealing to other students than are the instructors', which may date back a few years and therefore may be unfamiliar and uninteresting to today's young adults. Instructors should ask and discuss in advance just what strategic issue the excerpt illustrates. Once the students' interests are engaged, instructors can enlist their help in acquiring tapes or DVDs. Next, instructors need to come prepared with their videotapes wound to the exact point that they want the movie to start. If instructors need to show two or more disjoint excerpts from the same movie, they should bring the appropriate number of copies of the tape, each cued to the right place. If instructors are using DVDs, they need to make a note of the exact time (minutes and seconds) where the desired excerpt begins and practice in advance how to start the DVD quickly at the right point. If the students have to wait while instructors find the right place or the right button, or while instructors wind the tape to the next starting point, the students are distracted, and the movie or TV clips lose effectiveness.

Instructors should not assume that students know the general plots of the movies from which they are showing excerpts. They should prepare a brief explanation of the situation and the characters as they pertain to the excerpt and give the explanation just before starting the videotape. Instructors should not show a whole movie or a long clip when only a small point pertains to strategy; the students will get distracted by too many of the other incidental aspects.

\section{LITERATURE}

Novels and short stories are an even richer collection of illustrations of strategies in action. Les Liaisons Dangereuses must be an unmatched source for analyzing issues of credibility and of private information about motives (players' types). Historical literature also has valuable insights; Thucydides' The Peloponnesian War recounts debates and speeches that have outstanding 
expositions of strategic themes. In Shakespeare's Henry $V$, the famous speech before the battle of Agincourt is an excellent example of incentives to motivate soldiers to fight (see the discussion in Dixit and Nalebuff [1991, 161-63]), and Othello is full of strategic issues.

Many novels of crime and detection, with their themes of information and betrayal, are also excellent sources for illustrating these ideas. My personal favorite is Cogan's Trade by Higgins (1974). In it, the Boston mafia protects a high-stakes poker game. The person (Trattman) who runs the game himself arranges for it to be robbed. By the time the mafia bosses find this, all the fuss has died down, and because Trattman is well-liked, the bosses do nothing. However, some others got the idea that if they rob the game, Trattman would be the automatic suspect, and they would escape detection. The mafia bosses discover the truth, but they face a bigger problem-their reputation as effective protectors has been ruined and must be rebuilt. For this, they need a signaling strategy, and to make it credible in the standard Spencian manner, the signal has to be carried to excess, in this instance, literally to overkill. Cogan, the up-andcoming enforcer, explains the argument very clearly and explicitly to the consiglieri (Higgins 1974, ch. 8).

"It's his responsibility," Cogan said. "He did it before and he lied before and he fooled everybody, and I said ... 'They should've whacked him out before.'... Now it happened again. It's his responsibility for what the guys think...."

"He didn't do it," the driver said. "Not this time, anyway."

"That's not what everybody knows," Cogan said. "Shit, we're gonna have kids waiting in line, [to] knock them fuckin' games over, they open up again.... If he gets away with this, well, we might just as well forget it, once and for all, and just quit.... Tell [the godfather], ask him, where the guys come from, in the game.... They're not gonna come in, is all. Trattman did it before, [they think] Trattman did it again.... Trattman's gotta be hit."

When he gets the godfather's go-ahead to execute the overkill strategy of whacking out everyone involved (including Trattman), Cogan forms a temporary alliance with one of the miscreants in the second robbery, to get his cooperation in setting up another for the hit. However, the ally fails to think through the game and to solve it backward. Therefore, he does not realize that Cogan's promise to spare him is not credible. Of course, Cogan knows perfectly well what is going to happen: He responds to the consiglieri's question when outlining his plan for the hit (Higgins 1974, ch. 16): "Will he be all right?" . . "For a while. Not long, but a while."

This instance of the life-and-death importance of doing backward induction correctly is another useful lesson to emphasize from the novel.

Watts (2003) is an excellent compendium of excerpts from the literature bearing on economics. Some of them have game-theory content: for example, the excerpt from The Perfect Storm explains the prisoner's dilemma that leads to depletion of a fishery, and the excerpt from The Merchant of Venice has brilliant lessons about commitment and interpretation of an incompletely specified contract. Rasmusen (2000) includes some game-theory stories and cartoons in his 
collection of simpler articles on the subject. A game-theory equivalent of Watts' large economics anthology is eagerly awaited.

Pending such a collection, I have found that any substantial use of literature in today's game theory courses is problematic because it requires the students to do too much reading. If the Harry Potter novels had good strategic components, the problem might be solved. Unfortunately, the rules of the game in those books are hidden and keep changing somewhat randomly, making them poorly suited for illustrating game-theory ideas. If instructors are fortunate enough to have students who are well read or willing to read extensively for the course, they will get many good suggestions for the use of literature in their courses from Brams (1994).

\section{CONCLUDING REMARKS}

Imaginative use of gameplaying, movies, literature, and such other illustrations makes game theory much more fun to teach and to learn. This can be done without sacrificing any rigor. The ancillary material supplements and elucidates the theory; it does not supplant theory. Although I have barely touched on specific applications to teaching economics, I hope the few I have mentioned suggest numerous other ways to enrich that part of teaching also. In short, I believe this approach is a recipe to make everyone better off - an all-too-rare instance of a feasible Pareto improvement. The suggestions offered in this article should inspire some instructors to develop and teach courses of this kind. Enjoy, and I add, strategically (and shamelessly), use the Dixit-Skeath (2004) textbook!

\section{NOTE}

1. If the instructor introduced the prisoner's dilemma by developing a Cournot duopoly game, the students would have to learn two new things simultaneously. If the instructor asks "Why do shared dorm rooms usually become very untidy?" Students know the temptation to shirk from a familiar context and can easily tie it to the temptation to cut prices in duopoly, and then to the formal concepts of dominant strategies and the prisoner's dilemma.

\section{REFERENCES}

Anderson, S., and M. Engers. 2002. A beautiful blonde: A Nash coordination game. Working paper, University of Virginia. http://www.virginia.edu/economics/papers/engers/abb.PDF.

Brams, S. 1994. Game theory and literature. Games and Economic Behavior 6 (1): 32-54.

Brokaw, A. J., and T. E. Merz. 2004. Active learning with Monty Hall in a game theory class. Journal of Economic Education 35:259-68.

Bulow, J., and P. Klemperer. 1999. The generalized war of attrition. American Economic Review 89 (1): $175-89$.

Dixit, A., and B. Nalebuff. 1991. Thinking strategically. New York: W. W. Norton.

Dixit, A., and S. Skeath. 2004. Games of strategy. 2nd ed. New York: W. W. Norton.

Fehr, E., and S. Gächter. 2000. Cooperation and punishment in public goods experiments. American Economic Review 90 (4): 980-94.

Hammett, D. 1930. The Maltese falcon. New York: Knopf.

Higgins, G. V. 1974. Cogan's trade. New York: Knopf.

Hirshleifer, J., and J. G. Riley. 1992. The analytics of uncertainty and information. New York: Cambridge University Press.

Nagel, R. 1995. Unraveling in guessing games: An experimental study. American Economic Review 85 (5): 1313-26.

Nasar, S. 1998. A beautiful mind. New York: Simon and Schuster. 
Rasmusen, E., ed. 2000. Readings in games and information. Malden, MA: Blackwell.

Runyon, D. 1933. The idyll of Miss Sarah Brown. Collier's Magazine. Reprinted in Guys and Dolls. New York: Viking, 1992.

Schelling, T. C. 1960. The strategy of conflict. Cambridge, MA: Harvard University Press. 1966. Arms and influence. New Haven, CT: Yale University Press.

Simon, H. A., and J. Schaeffer. 1992. The game of chess. In Handbook of game theory, vol. I. eds., R. J. Aumann and S. Hart. Amsterdam: North-Holland.

Trandel, G. A. 1999. Using a TV game show to explain the concept of a dominant strategy. Journal of Economic Education 30: 133-40.

Von Neumann, J., and O. Morgenstern. 1953. Theory of games and economic behavior. 3rd ed. Princeton, NJ: Princeton University Press.

Watts, M. 2003. The literary book of economics. Wilmington, DE: ISI Books.

Williams, J. D. 1966. The compleat strategyst, rev. ed. New York: McGraw-Hill. (Reissued by Dover, 1986.)

\section{TRADE- OFFS}

An Introduction to Economic Reasoning and Social Issues

\section{HAROLD WINTER}

"This is a delightful book. It made me feel proud to be an economist."-Miles Kimball, University of Michigan

"Harold Winter's engaging volume, Trade-Offs, is a great starting point for introducing students to the economic approach to policy issues. Where other disciplines see absolutes, economics sees trade-

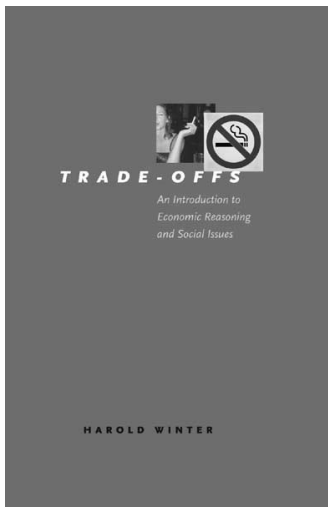
offs. And, as Winter shows, the guidance economics provides as to what these trade-offs are and what balance we should strike is often surprising. Trade-Offs illustrates the broad range of economic reasoning with a wealth of case studies that run the gamut from auto safety to organ transplants. This book will get students excited about learning economics." -W. Kip Viscusi, author of Smoke-Filled Rooms

Paper \$14.00 